\title{
Patient-Ventilator Interaction During Noninvasive Ventilation
}

\author{
Dean R Hess PhD RRT FAARC
}

\author{
Introduction \\ The Problem \\ Epidemiology of Asynchrony During NIV \\ The Interface and Asynchrony \\ The Ventilator and Asynchrony \\ Rebreathing \\ Leak Compensation \\ Trigger Asynchrony \\ Flow Asynchrony \\ Cycle Asynchrony \\ Mode Asynchrony \\ The Humidifier and Asynchrony \\ Ventilator-Neural Interactions \\ Strategies to Improve Synchrony During NIV \\ Conclusions
}

\begin{abstract}
There is arguably more evidence to support the use of noninvasive ventilation (NIV) than any other practice related to the care of patients with acute respiratory failure. Despite this strong evidence base, NIV seems to be under-utilized and the failure rate (need for intubation) may be as high as $40 \%$. Some of these failures potentially relate to asynchrony, although the relationship between asynchrony and NIV failure has not been well studied. Good NIV tolerance has been associated with success of NIV, and improved comfort has been associated with better synchrony. In one study a high rate of asynchrony occurred in $43 \%$ of patients during NIV. Asynchrony is commonly associated with leaks. Thus, reducing the leak related to the interface and using a ventilator with good leak compensation should reduce the rate of asynchrony. Asynchronies can also be related to the underlying disease process. This paper reviews issues related to asynchrony during NIV and suggests strategies that might be used to correct asynchrony when it occurs. Key words: asynchrony; noninvasive ventilation; mechanical ventilation; patientventilator interactions. [Respir Care 2011;56(2):153-165. (C) 2011 Daedalus Enterprises]
\end{abstract}

\section{Introduction}

Noninvasive ventilation (NIV) has received considerable academic and clinical attention in recent years. A

Dean R Hess PhD RRT FAARC is affiliated with Respiratory Care Services, Massachusetts General Hospital, Harvard Medical School, Boston, Massachusetts.

Dr Hess has disclosed relationships with Philips Respironics, Covidien, Impact, and Pari. number of narrative and systematic reviews have been written on this subject. ${ }^{1-8}$ For some conditions, such as

\footnotetext{
Dr Hess presented a version of this paper at the 46th ResPiRATORY CARE Journal Conference, "Patient-Ventilator Interaction," held March 19-21, 2010, in Cancún, Quintana Roo, Mexico.

Correspondence: Dean R Hess PhD RRT FAARC, Respiratory Care, Ellison 401, Massachusetts General Hospital, 55 Fruit Street, Boston MA 02114. E-mail: dhess@partners.org.
}

DOI: $10.4187 /$ respcare. 01049 
Table 1. Potential Causes of Failed Noninvasive Ventilation*

Poor patient selection: severity of illness, diagnosis

Progression of the underlying disease process

Wrong interface: size, leak $\dagger$

Wrong ventilator: poor leak compensation $\dagger$

Inappropriate ventilator settings $\dagger$

Clinician inexperience

* Defined as need for endotracheal intubation.

† May be related to asynchrony.

exacerbation of COPD or acute cardiogenic pulmonary edema, the use of NIV is considered first-line therapy and standard of care. In fact, an entire RESPIRATORY CARE Journal Conference was recently devoted to this subject. ${ }^{9}$ There is arguably more evidence to support the use of NIV than any other practice related to the care of patients with acute respiratory failure. Despite this strong evidence base, NIV seems to be under-utilized. ${ }^{10,11}$ In this paper I will review issues related to asynchrony during NIV and suggest strategies that might to used to correct asynchrony when it occurs.

\section{The Problem}

The evidence is clear that NIV reduces the need for endotracheal intubation and affords a survival benefit in appropriately selected patients. But an important number of patients fail NIV and require intubation. For example, in 14 randomized controlled trials enrolling patients with COPD exacerbation, there was a significant reduction in the need for intubation (risk ratio 0.42 , 95\% CI 0.33 0.53). ${ }^{7}$ However, $16 \%$ of patients who received NIV were intubated ( $40 \%$ of patients receiving usual medical care without NIV were intubated). Similarly, for acute cardiogenic pulmonary edema there is a significant reduction in the intubation rate with NIV (risk ratio $0.54,95 \%$ CI 0.33 0.86). ${ }^{8}$ Although more patients $(10 \%)$ are intubated with usual medical care, still 5\% of patients required intubation despite the use of NIV. A prospective observational study of NIV use in France reported a 38\% failure rate in a mixed population of patients with acute respiratory failure. ${ }^{12}$ Thus, it is unrealistic to expect NIV to avoid intubation in all patients. ${ }^{13}$ There are a number of potential causes of NIV failure (Table 1). Some of these failures potentially relate to asynchrony, although the relationship between asynchrony and NIV failure has not been well studied. Good NIV tolerance has been associated with success of NIV, ${ }^{13}$ and improved comfort has been associated with better synchrony. ${ }^{14}$

\section{Epidemiology of Asynchrony During NIV}

Vignaux et al ${ }^{14}$ conducted a prospective multicenter observation study to determine the prevalence of patient-

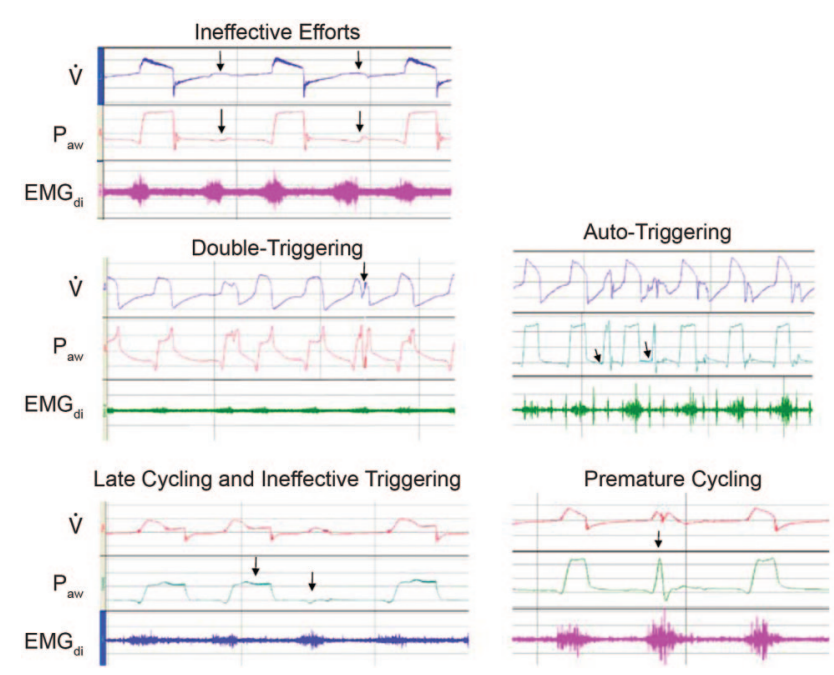

Fig. 1. Representative tracings of the 5 types of asynchrony. The arrows indicate ineffective efforts. $\mathrm{EMG}_{\mathrm{di}}=$ diaphragmatic electromyography tracing. $\mathrm{P}_{\mathrm{aw}}=$ airway pressure. $\dot{\mathrm{V}}=$ instantaneous flow. (Adapted from Reference 14, with permission.)

ventilator asynchrony in 60 patients receiving NIV for acute respiratory failure in 3 university hospitals. Airway pressure, flow, and surface diaphragmatic electromyography were recorded for $30 \mathrm{~min}$. Asynchrony events (ineffective triggering, double-triggering, auto-triggering, premature cycling, and delayed cycling) were detected via visual inspection of the recordings (Fig. 1). The asynchrony index was calculated as the number of asynchrony events divided by the total respiratory rate, computed as the sum of the number of ventilator cycles (triggered or not) and of wasted efforts:

\section{Asynchrony index $(\%)=$ number of asynchrony events/total respiratory rate $\times 100 \%$}

An asynchrony index $>10 \%$ was considered severe. Comfort was assessed using a visual analog scale.

In the study by Vignaux et al, ${ }^{14}$ auto-triggering was present in 8 patients (13\%), double-triggering in $9(15 \%)$, ineffective breaths in $8(13 \%)$, premature cycling in 7 $(12 \%)$ and late cycling in $14(23 \%)$. Eighteen patients presented with only one type of asynchrony, 10 patients had 2 types, and 4 had 3 types. Ineffective breaths and delayed cycling were the only 2 asynchronies likely to be grouped. An asynchrony index $>10 \%$ was present in 26 patients (43\%). Asynchrony events and associated respiratory parameters are shown in Table 2 . The 2 factors predictive of an asynchrony index $>10 \%$ were the level of pressure support and the magnitude of leaks. The comfort score was higher in patients with an asynchrony index $<10 \%$. No difference was observed in the intubation rate, ICU stay, or mortality between patients with or without an 


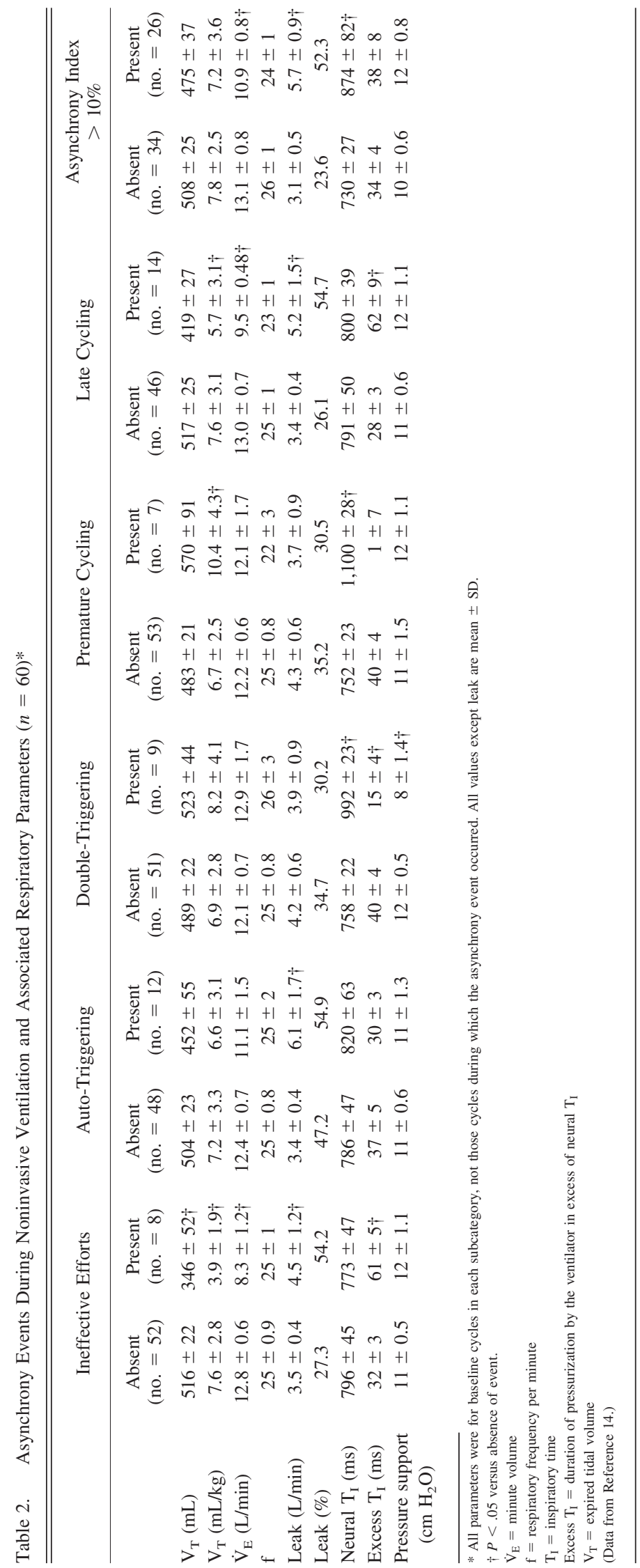


asynchrony index $>10 \%$. However, it should be noted that this is based on only a 30-min assessment of asynchrony, which may not have been representative of the total time of NIV.

\section{The Interface and Asynchrony}

The distinguishing feature between invasive ventilation and NIV is the interface. The interface for invasive ventilation is an endotracheal tube or tracheostomy tube, whereas the interface for NIV is a mouthpiece, nasal mask, nasal pillows, oronasal mask, total face mask, or helmet. ${ }^{15}$ The very nature of the interface promotes air leaks, which are common with NIV. Leaks may reduce the efficiency of NIV, reduce patient tolerance, cause awakenings and sleep fragmentation, and increase patient-ventilator asynchrony. For acute-care applications the oronasal mask is most often preferred by clinicians and patients. ${ }^{16,17}$

The interface can contribute to mechanical dead space. Although the in vitro difference in dead space between an oronasal mask $(205 \mathrm{~mL})$ and a nasal mask $(120 \mathrm{~mL})$ is substantial, the in vivo difference is smaller $(118 \mathrm{~mL}$ for oronasal mask vs $97 \mathrm{~mL}$ for nasal mask). ${ }^{18}$ Nonetheless, for a respiratory rate of 20 breaths/min, this adds about $2 \mathrm{~L} / \mathrm{min}$ of dead space. Saatci et $\mathrm{al}^{19}$ found that a face mask increased dynamic dead space from $32 \%$ to $42 \%$ of tidal volume. The use of PEEP also reduces the effective dead space of the mask. ${ }^{19}$ For ventilator/interface combinations that use a leak port, $\mathrm{CO}_{2}$ can be cleared from the mask by incorporating the leak port into the mask rather than the circuit. This effectively reduces the dead space of the mask. ${ }^{20}$

The helmet has a volume that is larger than the tidal volume. It behaves as a semi-closed environment, in which the increase in inspired partial pressure of $\mathrm{CO}_{2}$ is an important issue. Inspired $\mathrm{P}_{\mathrm{CO}_{2}}$ in a helmet depends on the amount of $\mathrm{CO}_{2}$ produced by the subject and the fresh gas flow that flushes the helmet. ${ }^{21,22}$ Taccone et $\mathrm{al}^{21}$ found that a $33 \%$ reduction in helmet volume had no effect on the amount of $\mathrm{CO}_{2}$ rebreathing. When they delivered CPAP with a ventilator and the helmet, there was considerable $\mathrm{CO}_{2}$ rebreathing (Fig. 2). Using either CPAP or NIV, the helmet affects $\mathrm{CO}_{2}$ clearance. ${ }^{15}$ High gas flow $(40-60 \mathrm{~L} /$ $\mathrm{min}$ ) is required to maintain a low inspired partial pressure of $\mathrm{CO}_{2} \cdot{ }^{21}$ Higher flow through the helmet has the potential to reduce patient comfort, due to increased noise and lower humidity, but this has not been well studied.

Rebreathing during NIV could potentially induce asynchrony because it increases respiratory drive and dyspnea. Banzett et al ${ }^{23}$ reported that subjects detected air hunger at an end-tidal $\mathrm{P}_{\mathrm{CO}_{2}} 4 \mathrm{~mm} \mathrm{Hg}$ over spontaneous end-tidal $\mathrm{P}_{\mathrm{CO}_{2}}$. They found the air hunger intolerable with an increase in end-tidal $\mathrm{P}_{\mathrm{CO}_{2}}$ of $11 \mathrm{~mm} \mathrm{Hg}$.
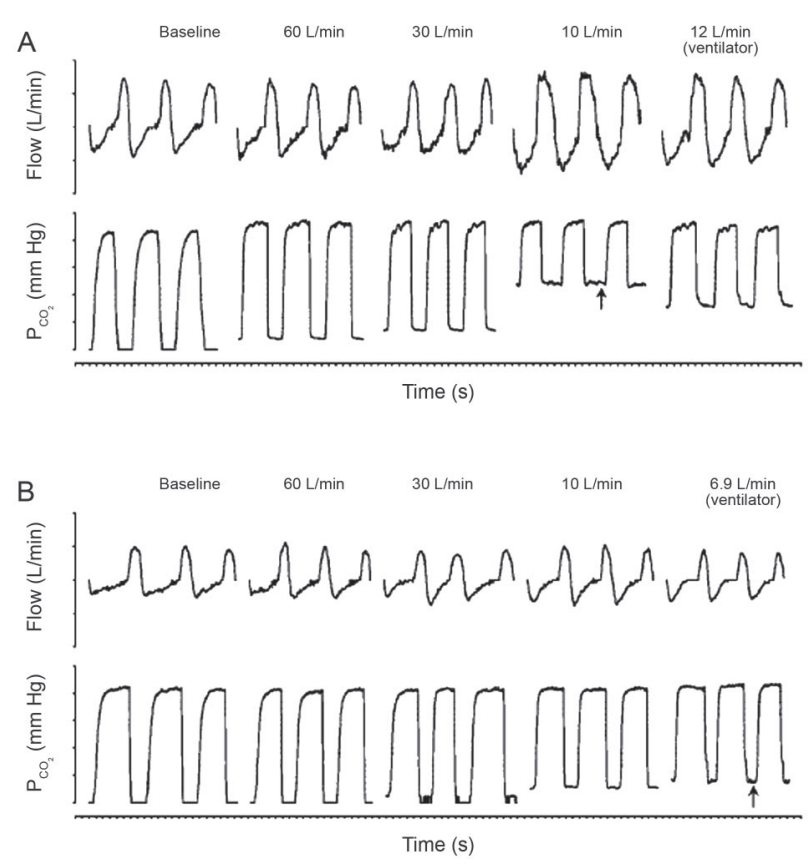

Fig. 2. A: Waveforms from a subject who had a baseline $\mathrm{CO}_{2}$ production of $273 \mathrm{~mL} / \mathrm{min}$. As the fresh gas flow through the helmet decreases from 60 to $10 \mathrm{~L} / \mathrm{min}(12.2 \mathrm{~L} / \mathrm{min}$ with the ventilator), the inspired $\mathrm{P}_{\mathrm{CO}_{2}}$ and the inspiratory flow increase substantially. $\mathrm{B}$ : Waveforms from a subject who had a baseline $\mathrm{CO}_{2}$ production of $109 \mathrm{~mL} / \mathrm{min}$. As the fresh gas flow through the helmet decreases from 60 to $10 \mathrm{~L} / \mathrm{min}(6.9 \mathrm{~L} / \mathrm{min}$ with the ventilator), the inspired $\mathrm{P}_{\mathrm{CO}_{2}}$ and inspiratory flow changes minimally. The arrows represent the highest value of $\mathrm{PiCO}_{2}$ recorded for each subject. (Adapted from Reference 21, with permission.)

In 6 healthy volunteers, Racca et al ${ }^{24}$ tested the hypothesis that the large internal volume and high compliance of the helmet might impair patient-ventilator interactions, compared with standard face mask. Use of the helmet to deliver pressure support ventilation (PSV) increased inspiratory muscle effort and patient-ventilator asynchrony, worsened $\mathrm{CO}_{2}$ clearance, and increased dyspnea, compared with standard face mask. Auto-triggered breaths accounted for $12 \%$ and $25 \%$ of the total minute ventilation, and for $10 \%$ and $23 \%$ of the total inspiratory muscle effort, during mask and helmet PSV, respectively. Racca et al concluded that PSV delivered via the helmet interface is less effective in unloading inspiratory muscles, compared with PSV delivered via standard face mask. Moerer et al ${ }^{25}$ reported that ventilator synchrony, trigger effort, and breathing comfort with the helmet were less impaired during PSV with the use of neurally adjusted ventilatory assist (NAVA), compared to conventional pressure or flow triggering and cycling.

Costa et $\mathrm{al}^{26}$ conducted a physiologic bench study and a human volunteer study that compared synchrony with invasive ventilation (endotracheal tube) and NIV with an oronasal mask or helmet as the interface. They found that 
patient-ventilator synchrony was significantly better with the endotracheal tube than with the mask or helmet. They also found that the helmet resulted in the worst synchrony, compared with the endotracheal tube or face mask.

Ventilators designed for NIV typically use a single-limb circuit with a leak port near the patient. The leak port provides the resistance against which the ventilator generates flow to produce pressure, and the leak port also serves as the exhalation port for the patient. Increasingly, the leak port is incorporated into the interface. Clinicians often mix interfaces from one manufacturer with ventilators from another manufacturer in an attempt to best fit the interface to the patient. However, this potentially creates an interface-ventilator mismatch, in which the ventilator does not function appropriately with the leak in the interface. Ventilators for NIV may allow the user to select the interface type, so that the interface-ventilator interaction is optimal. However, no ventilator has a setting for interfaces from another manufacturer.

Louis et $\mathrm{al}^{27}$ evaluated the effects of masks having different manufacturer-inserted leaks on ventilator performance. They found substantial differences in mask leak between devices that are widely used in clinical practice. The mask with the largest leak was associated with autotriggering and/or decreased inspiratory-trigger sensitivity with 3 of the 4 tested ventilators. The mask with the smallest intentional leak was associated with increased rebreathing. They concluded that, when switching to a mask that has different leak characteristics, evaluation is needed to adjust trigger sensitivity and pressure settings and to assure the absence of rebreathing.

\section{The Ventilator and Asynchrony}

Although any ventilator can be used for NIV, increasingly ventilators are used that are designed specifically for this application. ${ }^{28} \mathrm{Bi}$-level ventilators are designed specifically for NIV, and intermediate and critical-care ventilators increasingly have modes designed specifically for NIV. ${ }^{29}$ Pressure-targeted modes are used more commonly for NIV than are volume-targeted modes. For critical-care ventilators, dual-limb circuits are used, and these have inspiratory and expiratory valves: rebreathing is minimized by separation of the inspiratory and expiratory gases. Intermediate ventilators use a single-limb circuit with an exhalation valve near the patient. Bi-level ventilators use a single-limb circuit and a leak port, which serves as a passive exhalation port for the patient, and is incorporated into the circuit near the patient or into the interface.

\section{Rebreathing}

With the bi-level ventilators there is the potential for rebreathing. If rebreathing occurs, this may increase respi- ratory drive and contribute to asynchrony. ${ }^{30-32}$ Rebreathing is decreased if the leak port is in the mask rather than in the circuit, ${ }^{19,20}$ if oxygen is titrated into the mask rather than into the circuit, ${ }^{33}$ with a higher expiratory pressure, ${ }^{30}$ and with a plateau exhalation valve. ${ }^{30}$ Major determinants of rebreathing are the expiratory time and the flow through the circuit during exhalation. Increasing the expiratory pressure requires greater flow and thus decreases the amount of rebreathing; the minimum expiratory pressure setting on many bi-level ventilators is $3-4 \mathrm{~cm} \mathrm{H}_{2} \mathrm{O}$. Opening the ports on the interface increases leak, which increases the flow through the hose and flushes the hose to decrease rebreathing. The plateau exhalation valve effectively decreases rebreathing, but may increase the imposed expiratory resistance, ${ }^{31}$ and patients may find the plateau exhalation valve noisier and less attractive in appearance than the traditional leak port. ${ }^{34}$

\section{Leak Compensation}

Although ventilators have traditionally been leak intolerant, leaks are a reality with NIV. Moreover, the function of bi-level ventilators depends on the presence of a leak. Some bi-level ventilators allow the user to enter the interface that will be used, to allow more precise identification of the intentional leak. This approach, however, requires the use of an interface provided by that ventilator's manufacturer. As described previously, triggering and cycling issues may occur if an interface from one manufacturer is matched with a ventilator from a different manufacturer. Other bi-level ventilators allow the user to test the leak port as part of the pre-use procedure. Leak-detection algorithms must adjust for changes in leak with inspiratory and expiratory pressure changes, as well as changes that may occur breath-to-breath due to fit of the interface. Newer generations of bi-level ventilators use redundant leak-estimation algorithms.

Miyoshi et $\mathrm{al}^{35}$ evaluated the effects of gas leak on trigger, $\mathrm{F}_{\mathrm{IO}_{2}}$, and humidification during NIV with bi-level and critical-care ventilators. They found that the bi-level ventilators triggered properly at all levels of gas leak, and triggering was more effective than with the critical-care ventilators. $\mathrm{F}_{\mathrm{IO}_{2}}$ with the Respironics BiPAP S/T-D bilevel ventilator was affected by gas leak and could be predicted mathematically unless the gas leak was large. With large gas leaks, relative humidity was maintained, but absolute humidity decreased. Miyoshi et al concluded that gas leak affected triggering of ICU ventilators, $\mathrm{F}_{\mathrm{IO}_{2}}$ of the BiPAP S/T-D ventilator, and humidity delivered. Borel et $\mathrm{al}^{36}$ reported that the level of intentional leak in $7 \mathrm{com}-$ mercially available masks ranged from $30 \mathrm{~L} / \mathrm{min}$ to $45 \mathrm{~L} /$ min at a pressure of $14 \mathrm{~cm} \mathrm{H}_{2} \mathrm{O}$, which did not affect the trigger performance of bi-level ventilators. 
Many current-generation critical-care ventilators have NIV modes. NIV modes on critical-care ventilators vary in their leak-compensation capabilities. Vignaux et al ${ }^{37}$ performed a bench study of 8 ICU ventilators featuring an NIV mode. On most of the tested ventilators, leaks led to an increase in trigger delay and work load, a decrease in ability to reach the pressure target, and delayed cycling. The NIV mode partly or totally corrected these problems, but with large variations between machines. However, on some ventilators the NIV mode worsened the leak-induced dysfunction. Vignaux et al concluded that NIV modes can correct part or all of the issues with leaks that occur with NIV, but with wide variations in efficiency between machines.

In another bench study, Ferreira et $\mathrm{al}^{38}$ evaluated the ability of 9 critical-care ventilators to function in the presence of leaks, and compared this with a bi-level ventilator. At baseline, all of the ventilators were able to synchronize appropriately with the lung simulator. As the leak was increased, all of the ventilators except for the Vision (Respironics. Murrysville, Pennsylvania) and Servo-i (Maquet, Solna, Sweden) needed adjustment of trigger or cycle criteria to synchronize, and some transitioned to backup ventilation. Ferreira et al concluded that the Vision and Servo-i were the only ventilators that required no adjustments as they adapted to increasing leaks.

For acute-care applications there is value in being able to use the same ventilator for invasive ventilation, where leaks are usually absent, and for NIV, where leaks are always present. Leak compensation (control of trigger, cycle, and flow delivery) in critical-care ventilators is in its infancy. Probably this will improve as engineers develop more sophisticated algorithms for leak detection and compensation. Improvements in the design of interfaces will reduce the amount of leak. Clinicians will better fit the interface with experience in the application of NIV. With the combination of improved ventilator performance in the setting of leaks, better interfaces, and increased clinician experience, problems related to leaks should improve.

\section{Trigger Asynchrony}

Trigger asynchrony with NIV may be the result of leaks, which can produce either auto-triggering or ineffective triggers. Ineffective triggers can also be due to the underlying disease process, such as occurs with auto-PEEP in patients with COPD, and weak inspiratory efforts, such as occurs in patients with neuromuscular disease. Unlike the situation in the past, when using modern ventilators, trigger asynchrony is probably more often due to issues with pathophysiology than ventilator performance.

Modern ventilators can be flow-triggered, pressure-triggered, volume-triggered, or use sophisticated analysis of the flow pattern, such as the shape signal. ${ }^{39,40}$ Using an older-generation ventilator (Bird 8400 STi), Nava et al ${ }^{41}$ reported that, in patients with $\mathrm{COPD}$, flow-triggering reduced the inspiratory effort, compared with pressure-triggering. They attributed these findings to a reduction in dynamic auto-PEEP and in the time of valve opening with a flow trigger. However, the quality of pressure and flow triggers has improved on current-generation ventilations, and either approach is acceptable, provided that the trigger sensitivity is set appropriately. ${ }^{42-44}$

Several studies have evaluated automatic detection of ineffective triggering and double-triggering during mechanical ventilation. Mulqueeny et $\mathrm{al}^{45}$ evaluated an algorithm embedded in a ventilator system (ResMed ResControl II prototype) that is able to automatically detect the ineffective triggering and double-triggering in real time. They enrolled patients receiving PSV, half of whom were receiving NIV. The algorithm was designed to detect ineffective triggering as significant perturbations in the expiratory flow signal unaccompanied by a ventilator breath. Once flow and airway pressure signals have been passed through a noise filter and an unintentional-leak-compensation algorithm is applied to the flow signal, the first and second derivatives of the flow signal are calculated. For each perturbation detected, the amplitude and steepness of the decline are used to distinguish ineffective efforts from cardiogenic oscillations, coughs, and swallows. The detection algorithm is effective only after $600 \mathrm{~ms}$ into expiration, following the end of a ventilator breath. Doubletriggering was detectable on the airway pressure trace, when a ventilator cycle was followed by another positive cycle separated by less than $500 \mathrm{~ms}$. The detection of ineffective triggering and double-triggering from the algorithm was compared by 2 operators, with the clinical occurrence of the phenomena as assessed using the transdiaphragmatic pressure. Good accuracy with high specificity and sensitivity was reported with both conventional ventilation and NIV.

Cuvelier et $\mathrm{al}^{46}$ developed a mathematical analysis of ventilator tracings recorded during NIV to identify ineffective triggering efforts. They retrospectively analyzed tracings that were routinely recorded during the initiation of NIV in children with advanced stable cystic fibrosis lung disease and who had no previous experience with NIV. The waveforms were analyzed by 2 independent investigators. The ventilator tracings were analyzed with a computer algorithm designed to identify ineffective trigger efforts. The algorithm correctly identified $100 \%$ of triggered breaths and $95 \%$ of ineffective triggering efforts. Ineffective triggering was associated with a significant reduction in minute ventilation and inspiratory flow, and an increase in inspiratory efforts. Cuvelier et al concluded that noninvasive analysis of flow and airway pressure can reliably identify ineffective triggering efforts during NIV. 
Fast
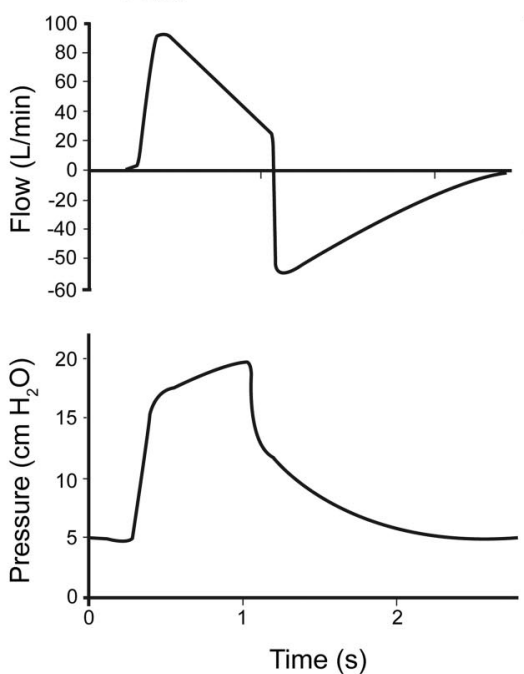

Moderate
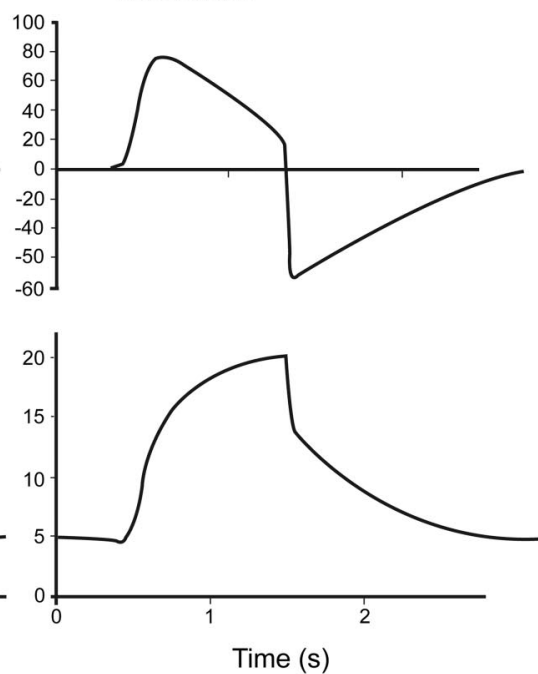

Slow
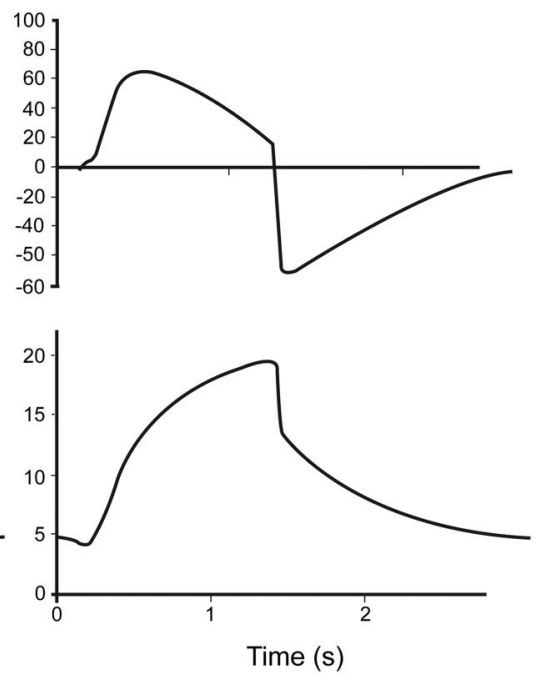

Fig. 3. Flow and pressure waveforms for 3 rise times (pressurization rates) at a pressure support of $20 \mathrm{~cm} \mathrm{H}_{2} \mathrm{O}$. Note the effect of rise time on flow at the initiation of the inspiratory phase. (Adapted from Reference 44.)

The ability to detect ineffective trigger efforts noninvasively and automatically during NIV is attractive. This could conceivably prompt clinicians of the presence of asynchrony and the need to make ventilator adjustments, such as PEEP to counter-balance auto-PEEP. It could also be used to assess patient response to efforts to improve synchrony. However, additional evaluation is necessary before such systems are ready for incorporation into clinical practice. For example, high level evidence is lacking that automatic detection of ineffective trigger efforts leads to clinician efforts that ultimately result in better synchrony during NIV.

\section{Flow Asynchrony}

Pressure-targeted ventilation is most commonly used for NIV. From a practical standpoint, most ventilators designed for NIV do not provide volume control ventilation (VCV). With bi-level ventilators the clinician sets the inspiratory positive airway pressure (IPAP) and the expiratory positive airway pressure (EPAP); the difference between IPAP and EPAP is the level of pressure support or pressure control. Compared with VCV, clinicians commonly believe that the variable inspiratory flow associated with pressure-targeted ventilation improves patient comfort and patient-ventilator synchrony. ${ }^{47} \mathrm{With} \mathrm{VCV}$, flow delivery is determined by the flow setting on the ventilator. With pressure-targeted ventilation, the determinants of inspiratory flow are the inspiratory pressure setting and respiratory mechanics (resistance and compliance). Borel et $\mathrm{al}^{36}$ reported that the capacity to achieve and maintain IPAP was significantly decreased when intentional leaks increased. This suggests that flow delivery to the patient may be reduced in the presence of leaks, which could result in flow asynchrony.

Girault et $\mathrm{al}^{48}$ reported that PSV and VCV provided similarly improved breathing pattern and gas exchange. These effects were associated with higher respiratory discomfort with VCV than with PSV. Navalesi et al ${ }^{18}$ compared PSV and pressure control ventilation (PCV) (in other words, flow-cycled vs time-cycled pressure-targeted ventilation), and reported that NIV provided better ventilation and gas exchange, compared with unassisted spontaneous breathing, irrespective of the ventilator mode. There were no differences between modes in tolerance of ventilation, gas exchange, or breathing pattern. In patients with stable cystic fibrosis, Fauroux et $\mathrm{al}^{49}$ found that either PSV or VCV decreased respiratory muscle unloading.

For pressure-targeted ventilation, the rise-time control refers to the time required for the ventilator to reach the pressure target at the onset of inspiration. ${ }^{44}$ It is the rate of pressurization at the initiation of the inspiratory phase. Rise-time adjustment during NIV allows the clinician to set the flow at the onset of the inspiratory phase during PSV. A fast rise time is associated with high peak flow, and a slow rise time is associated with a low peak flow (Fig. 3). Theoretically, patients with a high respiratory drive should be more synchronous with the ventilator with a fast rise time, whereas those with a lower respiratory drive might be more synchronous with a slower rise time.

There are several potential drawbacks to a high inspiratory flow at the onset of inspiration, such as might result from a higher pressurization rate..$^{50}$ If the flow is higher at the onset of inspiration, the inspiratory phase may be pre- 
maturely terminated if the ventilator cycles to the expiratory phase at a flow that is a fraction of the peak inspiratory flow. Several studies have suggested the existence of a flow-related inspiratory terminating reflex. ${ }^{51-53}$ Activation of this reflex shortens neural inspiration, which could result in brief, shallow inspiratory efforts, particularly at low settings of PSV. Although the clinical effects of this inspiratory flow-terminating reflex during NIV remain to be determined, it suggests that manipulation of rise time during PSV may result in a complex interaction between flow delivery from the ventilator function and physiology. A faster rise time has been reported to better unload the respiratory muscles of patients with COPD during NIV, but this may be accompanied by substantial air leaks and poor tolerance..$^{54}$ Thus, the physiologic benefit that might occur with rise-time adjustment should be balanced against patient comfort.

\section{Cycle Asynchrony}

During continuous mandatory ventilation (VCV or PCV) the inspiratory phase is time-cycled. For these breath types the presence of leaks will not affect the inspiratory time. However, PSV is normally flow-cycled. If the leak flow is greater than the flow cycle criterion or threshold, the inspiratory phase will continue indefinitely. However, there is usually a secondary time cycle should this occur, which is fixed on some ventilators (eg, $3 \mathrm{~s}$ ) but adjustable on others.

If the inspiratory time is prolonged due to leaks, expiratory time is shortened if respiratory rate is constant, which could produce auto-PEEP. As discussed previously, auto-PEEP makes triggering more difficult. Thus, cycle asynchrony could produce trigger asynchrony. If the patient fails to trigger, expiratory time will increase, the amount of auto-PEEP decreases, and the patient is then able to trigger. The result is variability in the respiratory rate provided by the ventilator. If auto-PEEP increases, the delivered tidal volume for a fixed pressure-support setting is less. This results in variability in tidal volume delivery.

Using an older-generation bi-level ventilator, Mehta et $\mathrm{al}^{55}$ reported that a large leak interfered with cycling of the ventilator and shortened the expiratory time. Calderini et $\mathrm{al}^{56}$ reported that, in the presence of leaks, time-cycled PCV provided better synchrony and patient comfort than flow-cycled PSV during NIV. Battisti et al ${ }^{57}$ reported delayed cycling in the presence of leaks with bi-level ventilators. Borel et al, ${ }^{36}$ however, found that expiratory cycling was not affected by the level of intentional leaks in masks, except with COPD conditions.

Hotchkiss et al ${ }^{58}$ used a mathematical model and lung model to simulate the issue of leaks on ventilator performance. They found that PSV applied in the context of an inspiratory leak resulted in breath-to-breath variation in the inspiratory phase, resulting in auto-PEEP if the respiratory rate was fixed, or variability in respiratory rate, inspiratory time, and auto-PEEP if the rate was varied. This was most likely when the respiratory system time constant was long relative to the respiratory rate, which occurs in patients with COPD. A bench study by Adams et $\mathrm{l}^{59}$ predicted a relatively narrow range for inspiratory flow cycle that provides adequate ventilatory support without causing hyperinflation in patients with COPD.

To avoid prolonged inspiration with PSV, unintentional leaks should be minimized, and use of a ventilator with good leak compensation is ideal. Some bi-level ventilators use redundant measures to determine end of inspiration. For example, the Philips Respironics bi-level ventilators use the shape signal and spontaneous expiratory threshold. The spontaneous expiratory threshold is an electronic signal that rises in proportion to the inspiratory flow rate on each breath. When the spontaneous expiratory threshold and actual patient flow are equal, the ventilator cycles to exhalation. The maximum inspiratory time is adjustable on some ventilators, and some ventilators allow the flow cycle criteria to be adjusted. Note that the effect of a higher flow cycle as a percentage of peak inspiratory flow translates to a shorter inspiratory time (Fig. 4).

Using a lung model and healthy volunteers, Costa et $\mathrm{al}^{26}$ evaluated the effects of rise time and flow cycle criteria during NIV using PSV with a Puritan Bennett 840 ventilator. They compared a rapid rise time $(80 \%)$ and high flow cycle $(60 \%)$ to a slow rise time $(20 \%)$ and low flow cycle $(5 \%)$. At a respiratory rate of 30 breaths/min the combination of $20 \%$ rise time and $5 \%$ flow cycle produced the worst synchrony, with a higher rate of wasted efforts, compared with a rise time of $80 \%$ and a flow cycle of $60 \%$. This suggests that a shorter rise time and a higher flow cycle should be considered during NIV when used in patients with tachypnea.

\section{Mode Asynchrony}

NAVA and proportional assist ventilation (PAV) are modes intended to improve patient-ventilator synchrony. ${ }^{60}$ NAVA has been reported to improve synchrony during NIV when a helmet is used. ${ }^{25}$ For PAV, Gay et al ${ }^{61}$ reported better patient tolerance with PAV, compared to PSV during NIV. However, it is unclear whether the improved tolerance was due to improved synchrony, as synchrony per se was not evaluated in this study.

Patient-ventilator interaction can be affected if respiratory drive decreases during NIV. In the absence of a backup rate during PSV, apnea may occur. Thus, it would seem prudent to set a backup rate during NIV. A decreased respiratory drive can also result in a decreased tidal volume with PSV. Adaptive servo-ventilation (adapt SV) on the ResMed bi-level ventilator and average volume-assured pres- 

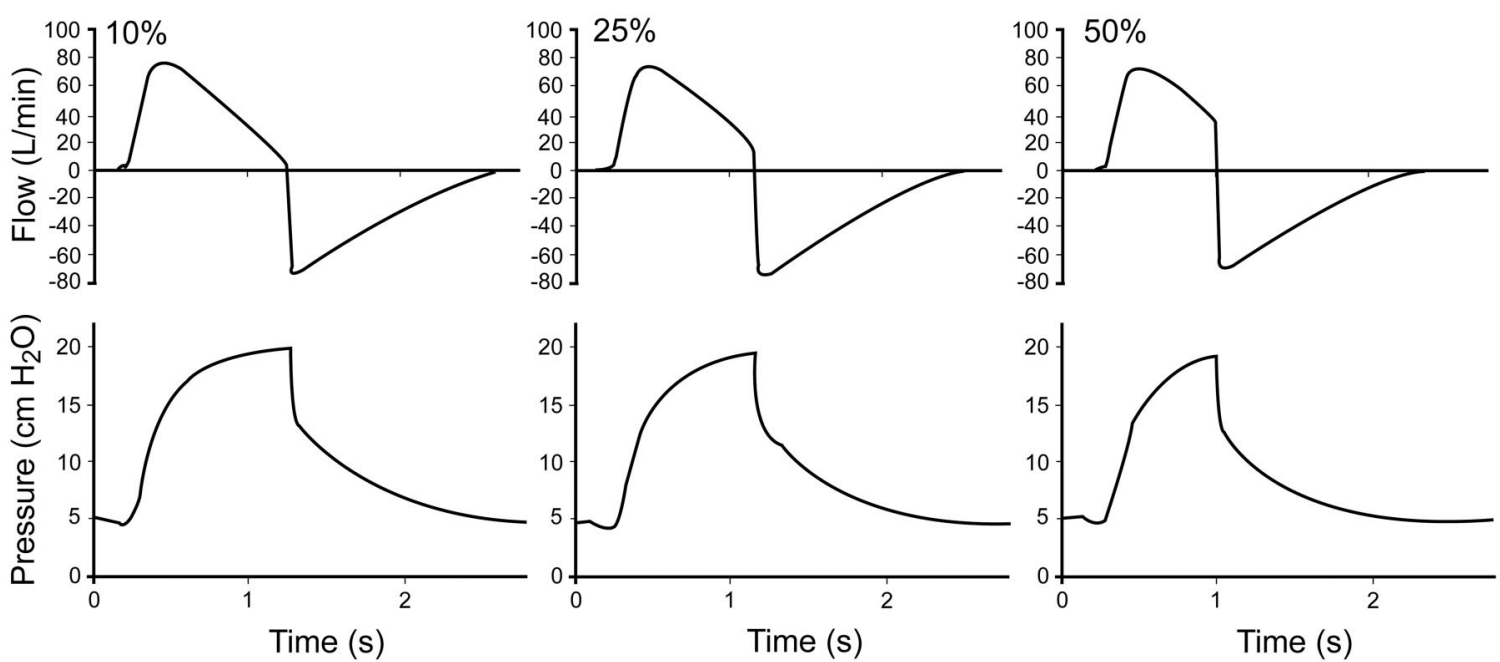

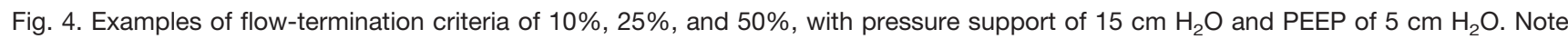
the effect of flow-termination criteria on inspiratory time. (Adapted from Reference 44.)

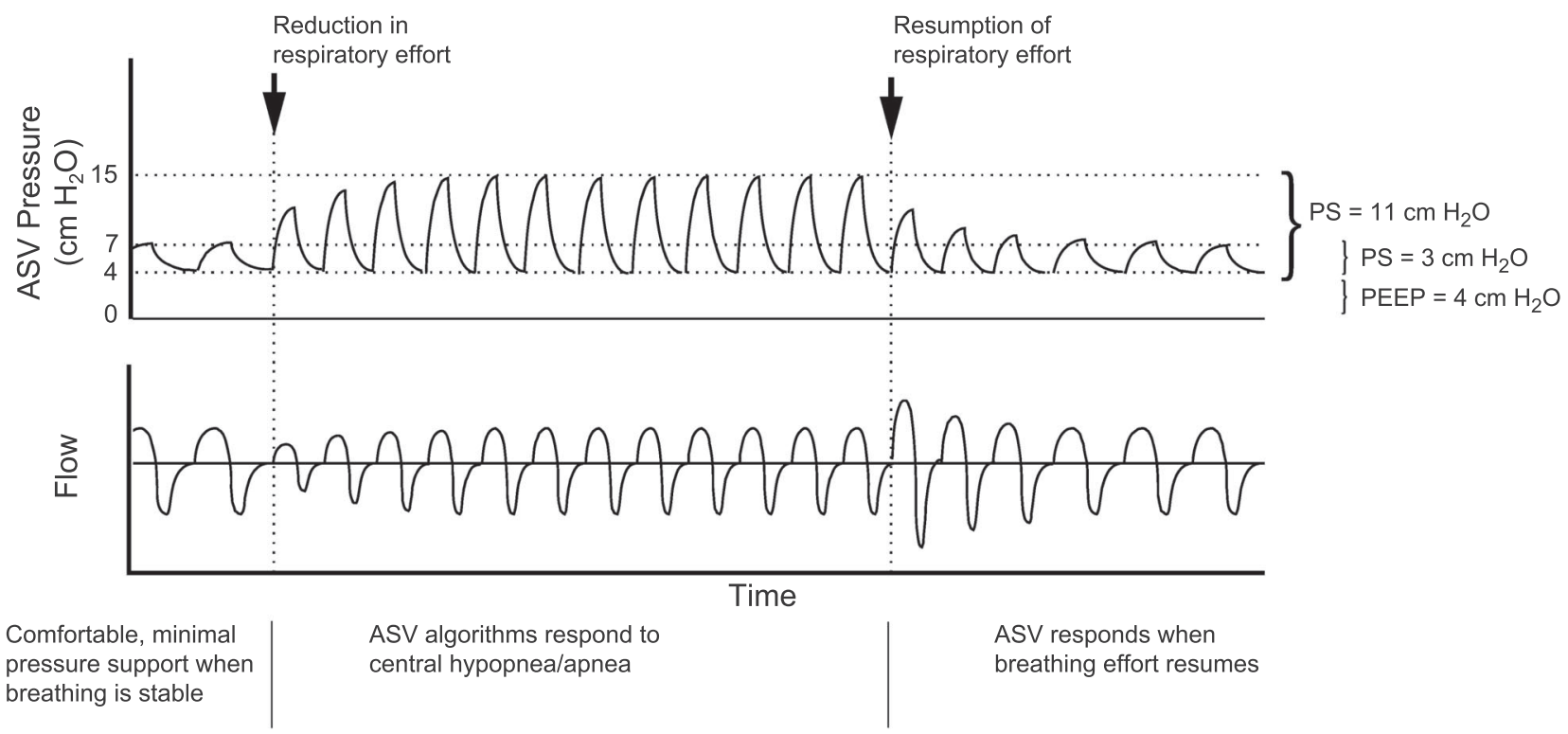

Fig. 5. Adaptive Servo Ventilation (ASV). PS = pressure support. (Courtesy of ResMed.)

sure support (AVAPS) on the Respironics bi-level ventilators have been developed to address these issues.

With adapt SV (Fig. 5) the ventilator algorithm uses 3 variables to achieve synchronization between pressure support and the patient's breathing: (1) the patient's average respiratory rate; (2) the direction, magnitude, and rate of change of the patient's air flow; and (3) a backup respiratory rate of 15 breaths/min. When central apnea or hypopnea occurs, support initially continues to reflect the patient's breathing pattern. If apnea or hypopnea persists, the ventilator uses the backup respira- tory rate. When breathing resumes and ventilation exceeds the target, pressure support is reduced to the minimum of $3 \mathrm{~cm} \mathrm{H}_{2} \mathrm{O}$. Adaptive servo ventilation has been used primarily in the treatment of patients with sleep-disordered breathing associated with chronic congestive heart failure and Cheyne-Stokes respirations or periodic breathing. ${ }^{62-73}$ Whether it might also have application during NIV in patients with acute respiratory failure has not been studied, to my knowledge.

AVAPS (Fig. 6) maintains a tidal volume equal to or greater than the target tidal volume by automatically con- 


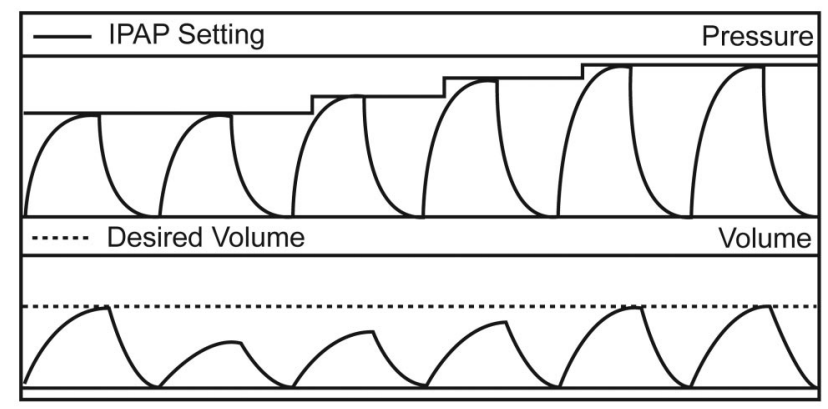

Fig. 6. Average volume-assured pressure support. IPAP = inspiratory positive airway pressure. (Courtesy of Respironics.)

trolling the minimum and maximum IPAP settings. AVAPS averages tidal volume over time and gradually changes the IPAP over several minutes to achieve the target tidal volume. If patient effort decreases, IPAP is increased to maintain the target tidal volume. On the other hand, if patient effort increases, IPAP is reduced. Because AVAPS is a form of adaptive PCV, there is a concern that the ventilator will inappropriately decrease support if respiratory drive increases. ${ }^{74}$ There have been reports of the use of AVAPS in patients with obesity hypoventilation syndrome ${ }^{75}$ and in stable patients with COPD and hypercapnia. ${ }^{76}$ However, to my knowledge there have been no reports of the use of AVAPS in patients with acute respiratory failure.

\section{The Humidifier and Asynchrony}

Although the use of humidification during NIV is controversial, ${ }^{77}$ it is commonly used to improve patient comfort and to prevent drying of the upper airway. Humidification can be provided by either active (heated humidifier) or passive (heat-and-moisture exchanger [HME]) methods. The results of one study suggest that either a heated humidifier or an HME are effective during NIV. ${ }^{78}$ However, there are several important limitations of that study: (1) the subjects were normal volunteers, (2) the evaluation period was very short (15 min), and (3) evaluations were made with CPAP rather than NIV. Thus, the clinical relevance of those results is unclear.

From the perspective of patient-ventilator interaction, the results of several studies suggest that use of an HME during NIV is not prudent. Lellouche et $\mathrm{al}^{79}$ reported that minute ventilation was significantly higher with an HME than with heated humidifier for a similar $\mathrm{P}_{\mathrm{aCO}}$. Moreover, the HME was associated with a greater increase in work of breathing and indexes of patient effort. In fact, NIV with an HME failed to decrease work of breathing, compared to baseline. Similarly, Jaber et al ${ }^{80}$ reported that $\mathrm{P}_{\mathrm{aCO}}$ was significantly higher with an HME than with a heated humidifier. They concluded that, during NIV, the increased dead space of an HME may negatively affect respiratory function and gas exchange. Based on this evidence, the use of an HME during NIV is not recommended, due to the increased respiratory work load related to the resistance and dead space of the device. This additional work load and higher $\mathrm{P}_{\mathrm{aCO}}$ could potentially lead to asynchrony.

\section{Ventilator-Neural Interactions}

Raux et al ${ }^{81}$ administered PSV via NIV to 7 healthy volunteers with continuous electroencephalographic recordings. The ventilator settings were first adjusted to make the subjects feel comfortable, and then modified to induce respiratory discomfort. This was achieved by setting the ventilator to a higher trigger level, reducing the slope of the rise in pressure support, and reducing the level of pressure support. To identify respiratory-related premotor activity, a minimum of 80 pre-inspiratory electroencephalographic epochs were averaged. Raux et al found that altering ventilator settings induced respiratory discomfort, and this was associated with premotor potentials in all cases, which disappeared upon return to comfortable settings. Thus, it appears that patient-ventilator asynchrony in healthy humans is associated with an activation of higher cerebral areas. Raux et al suggested that premotor potentials could thus be markers of patient-ventilator asynchrony at the brain level.

Evans et al ${ }^{82}$ induced air hunger in 6 healthy subjects while measuring cerebral activity using functional magnetic resonance imaging. They found that the insula appears to be important in dyspnea perception. Noteworthy is that the insula participates in the awareness of primal sensations such as pain, hunger, and thirst. The insula also evaluates distressing stimuli carrying negative emotional valence. To the extent that asynchrony relates to dyspnea, these results suggest that asynchrony may have ventilatorneural implications.

\section{Strategies to Improve Synchrony During NIV}

Although evidence is lacking for improved outcomes when there is better patient-ventilator interaction with NIV, there is a compelling argument to improve synchrony so that patients will be more comfortable. Asynchrony can be recognized from patient examination (eg, tachypnea, accessory muscle use, nasal flaring); patient interview (eg, dyspnea); and examination of ventilator waveforms (ineffective triggering, double-triggering, auto-triggering, premature cycling, and delayed cycling; see Fig. 1). With an understanding of potential causes of asynchrony during NIV, a number of strategies can be implemented to address this clinical problem (Table 3). Note that these strategies are a combination of ventilator adjustments and treatment of the underlying disease process. 
Table 3. Strategies to Improve Synchrony With Noninvasive Ventilation

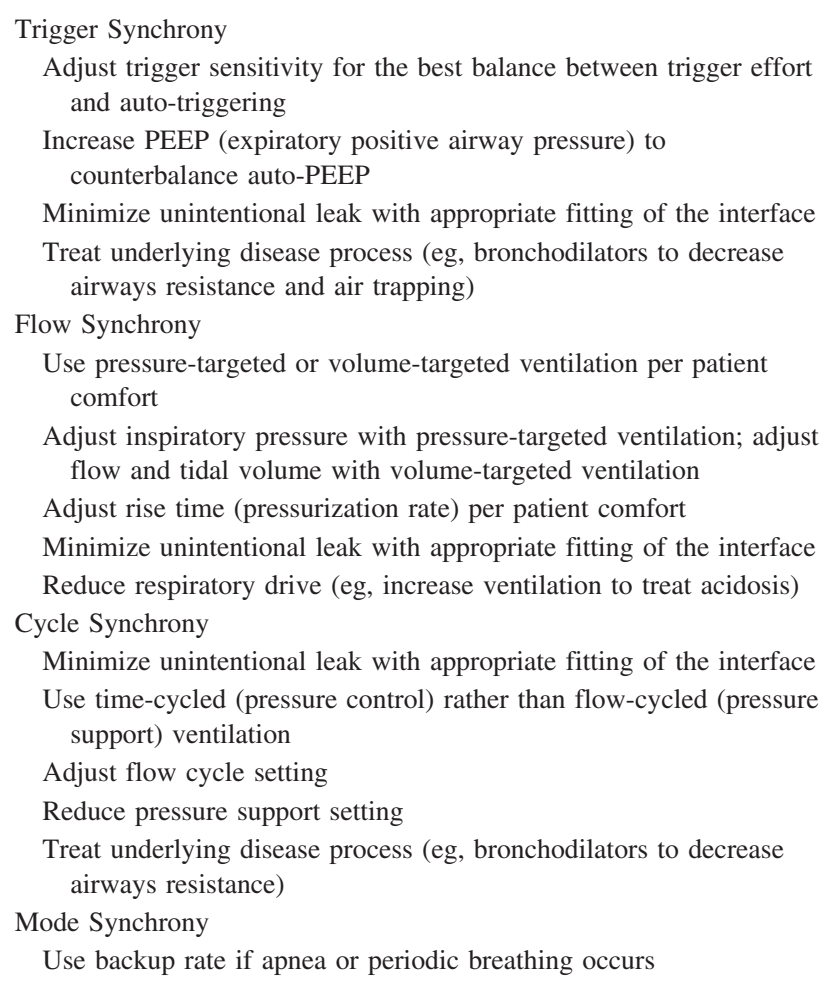

Ventilator adjustments to improve synchrony should be systematically applied, and each intervention assessed by patient examination, the patient's subjective reports of dyspnea and comfort, and careful assessment of the ventilator waveforms. Synchrony may not need to be perfect, provided that the patient is comfortable and gas exchange is adequate. Attention should also be given to treatment of pain and anxiety. ${ }^{83}$

For many patients receiving NIV, the underlying physiology is dynamic and there may be moment-by-moment changes in respiratory drive. This may require frequent manipulations of ventilator settings by clinicians, particularly when the patient is at an unstable point in the disease process. Such attention might be impractical in everyday clinical reality. This makes a case for ventilator algorithms that automatically detect asynchrony. Such systems could prompt clinicians of the presence of asynchrony, and they could be used to assess patient response to efforts to improve synchrony. It might also be possible to develop closed-loop systems that would automatically titrate PEEP in the presence of missed trigger efforts, or adjust the rise time in response to changes in respiratory drive, or adjust the cycle criteria when ventilator inspiratory time does not match neural inspiratory time.

\section{Conclusions}

Evidence is lacking that better patient-ventilator synchrony is related to better success of NIV. However, to the extent that patient-ventilator interaction, dyspnea, and comfort are related, no one can argue against efforts to improve synchrony during NIV.

\section{REFERENCES}

1. Agarwal R, Aggarwal AN, Gupta D, Jindal SK. Role of noninvasive positive-pressure ventilation in postextubation respiratory failure: a meta-analysis. Respir Care 2007;52(11):1472-1479.

2. Burns KE, Adhikari NK, Meade MO. A meta-analysis of noninvasive weaning to facilitate liberation from mechanical ventilation. Can J Anaesth 2006;53(3):305-315.

3. Keenan SP, Gregor J, Sibbald WJ, Cook D, Gafni A. Noninvasive positive pressure ventilation in the setting of severe, acute exacerbations of chronic obstructive pulmonary disease: more effective and less expensive. Crit Care Med 2000;28(6):2094-2102.

4. Keenan SP, Sinuff T, Cook DJ, Hill NS. Does noninvasive positive pressure ventilation improve outcome in acute hypoxemic respiratory failure? A systematic review. Crit Care Med 2004;32(12):2516-2523.

5. Mehta S, Al-Hashim AH, Keenan SP. Noninvasive ventilation in patients with acute cardiogenic pulmonary edema. Respir Care 2009; 54(2):186-195; discussion 195-197.

6. Nava S, Hill N. Non-invasive ventilation in acute respiratory failure. Lancet 2009;374(9685):250-259.

7. Ram FS, Picot J, Lightowler J, Wedzicha JA. Non-invasive positive pressure ventilation for treatment of respiratory failure due to exacerbations of chronic obstructive pulmonary disease. Cochrane Database Syst Rev 2004;(1):CD004104.

8. Weng CL, Zhao YT, Liu QH, Fu CJ, Sun F, Ma YL, et al. Metaanalysis: noninvasive ventilation in acute cardiogenic pulmonary edema. Ann Intern Med 2010;152(9):590-600.

9. Kallet RH. Noninvasive ventilation in acute care: controversies and emerging concepts. Respir Care 2009;54(2):259-263.

10. Bierer GB, Soo Hoo GW. Noninvasive ventilation for acute respiratory failure: a national survey of Veterans Affairs hospitals. Respir Care 2009;54(10):1313-1320.

11. Hess DR, Pang JM, Camargo CA Jr. A survey of the use of noninvasive ventilation in academic emergency departments in the United States. Respir Care 2009;54(10):1306-1312.

12. Demoule A, Girou E, Richard JC, Taille S, Brochard L. Increased use of noninvasive ventilation in French intensive care units. Intensive Care Med 2006;32(11):1747-1755.

13. Hess DR. How to initiate a noninvasive ventilation program: bringing the evidence to the bedside. Respir Care 2009;54(2):232-243; discussion 235-243.

14. Vignaux L, Vargas F, Roeseler J, Tassaux D, Thille AW, Kossowsky MP, et al. Patient-ventilator asynchrony during non-invasive ventilation for acute respiratory failure: a multicenter study. Intensive Care Med 2009;35(5):840-846.

15. Nava S, Navalesi P, Gregoretti C. Interfaces and humidification for noninvasive mechanical ventilation. Respir Care 2009;54(1):71-84.

16. Crimi C, Noto A, Princi P, Esquinas A, Nava S. A European survey of non- invasive ventilation (NIV) practices. Eur Respir J 2010.

17. Kwok H, McCormack J, Cece R, Houtchens J, Hill NS. Controlled trial of oronasal versus nasal mask ventilation in the treatment of acute respiratory failure. Crit Care Med 2003;31(2):468-473.

18. Navalesi P, Fanfulla F, Frigerio P, Gregoretti C, Nava S. Physiologic evaluation of noninvasive mechanical ventilation delivered with three 
types of masks in patients with chronic hypercapnic respiratory failure. Crit Care Med 2000;28(6):1785-1790.

19. Saatci E, Miller DM, Stell IM, Lee KC, Moxham J. Dynamic dead space in face masks used with noninvasive ventilators: a lung model study. Eur Respir J 2004;23(1):129-135.

20. Schettino GP, Chatmongkolchart S, Hess DR, Kacmarek RM. Position of exhalation port and mask design affect $\mathrm{CO}_{2}$ rebreathing during noninvasive positive pressure ventilation. Crit Care Med 2003; 31(8):2178-2182.

21. Taccone P, Hess D, Caironi P, Bigatello LM. Continuous positive airway pressure delivered with a "helmet": effects on carbon dioxide rebreathing. Crit Care Med 2004;32(10):2090-2096.

22. Mojoli F, Iotti GA, Gerletti M, Lucarini C, Braschi A. Carbon dioxide rebreathing during non-invasive ventilation delivered by helmet: a bench study. Intensive Care Med 2008;34(8):1454-1460.

23. Banzett RB, Lansing RW, Evans KC, Shea SA. Stimulus-response characteristics of $\mathrm{CO}_{2}$-induced air hunger in normal subjects. Respir Physiol 1996;103(1):19-31.

24. Racca F, Appendini L, Gregoretti C, Stra E, Patessio A, Donner CF, et al. Effectiveness of mask and helmet interfaces to deliver noninvasive ventilation in a human model of resistive breathing. $\mathrm{J}$ Appl Physiol 2005;99(4):1262-1271.

25. Moerer O, Beck J, Brander L, Costa R, Quintel M, Slutsky AS, et al. Subject-ventilator synchrony during neural versus pneumatically triggered non-invasive helmet ventilation. Intensive Care Med 2008; 34(9):1615-1623.

26. Costa R, Navalesi P, Spinazzola G, Ferrone G, Pellegrini A, Cavaliere $\mathrm{F}$, et al. Influence of ventilator settings on patient-ventilator synchrony during pressure support ventilation with different interfaces. Intensive Care Med 2010;36(8):1363-1370.

27. Louis B, Leroux K, Isabey D, Fauroux B, Lofaso F. Effect of manufacturer-inserted mask leaks on ventilator performance. Eur Respir J 2010;35(3):627-636.

28. Hess DR. Positive pressure ventilators. In: Elliot MW, Nava S, Schönhofer B, editors. Non-invasive ventilation and weaning principles and practice. London: Hodder and Stoughton; 2010:13-23.

29. Chatburn RL. Which ventilators and modes can be used to deliver noninvasive ventilation? Respir Care 2009;54(1):85-101.

30. Ferguson GT, Gilmartin M. $\mathrm{CO}_{2}$ rebreathing during BiPAP ventilatory assistance. Am J Respir Crit Care Med 1995;151(4):1126-1135.

31. Lofaso F, Brochard L, Hang T, Lorino H, Harf A, Isabey D. Home versus intensive care pressure support devices. Experimental and clinical comparison. Am J Respir Crit Care Med 1996;153(5):1591-1599.

32. Lofaso F, Brochard L, Touchard D, Hang T, Harf A, Isabey D. Evaluation of carbon dioxide rebreathing during pressure support ventilation with airway management system (BiPAP) devices. Chest 1995;108(3):772-778.

33. Thys F, Liistro G, Dozin O, Marion E, Rodenstein DO. Determinants of $\mathrm{F}_{\mathrm{IO} 2}$ with oxygen supplementation during noninvasive two-level positive pressure ventilation. Eur Respir J 2002;19(4):653-657.

34. Hill NS, Carlisle C, Kramer NR. Effect of a nonrebreathing exhalation valve on long-term nasal ventilation using a bilevel device. Chest 2002;122(1):84-91.

35. Miyoshi E, Fujino Y, Uchiyama A, Mashimo T, Nishimura M. Effects of gas leak on triggering function, humidification, and inspiratory oxygen fraction during noninvasive positive airway pressure ventilation. Chest 2005;128(5):3691-3698.

36. Borel JC, Sabil A, Janssens JP, Couteau M, Boulon L, Levy P, et al. Intentional leaks in industrial masks have a significant impact on efficacy of bilevel noninvasive ventilation: a bench test study. Chest 2009;135(3):669-677.

37. Vignaux L, Tassaux D, Jolliet P. Performance of noninvasive ventilation modes on ICU ventilators during pressure support: a bench model study. Intensive Care Med 2007;33(8):1444-1451.
38. Ferreira JC, Chipman DW, Hill NS, Kacmarek RM. Bilevel vs ICU ventilators providing noninvasive ventilation: effect of system leaks: a COPD lung model comparison. Chest. 2009;136(2):448-456.

39. Prinianakis G, Kondili E, Georgopoulos D. Effects of the flow waveform method of triggering and cycling on patient-ventilator interaction during pressure support. Intensive Care Med 2003;29(11):1950-1959.

40. Sassoon CHS. Triggering of the ventilator in patient-ventilator interactions. Respir Care 2011;56(1)39-48; discussion 48-51.

41. Nava S, Ambrosino N, Bruschi C, Confalonieri M, Rampulla C. Physiological effects of flow and pressure triggering during noninvasive mechanical ventilation in patients with chronic obstructive pulmonary disease. Thorax 1997;52(3):249-254.

42. Richard JC, Carlucci A, Breton L, Langlais N, Jaber S, Maggiore S, et al. Bench testing of pressure support ventilation with three different generations of ventilators. Intensive Care Med 2002;28(8):1049-1057.

43. Thille AW, Lyazidi A, Richard JC, Galia F, Brochard L. A bench study of intensive-care-unit ventilators: new versus old and turbinebased versus compressed gas-based ventilators. Intensive Care Med 2009;35(8):1368-1376.

44. Hess DR. Ventilator waveforms and the physiology of pressure support ventilation. Respir Care 2005;50(2):166-183; discussion 183-186.

45. Mulqueeny Q, Redmond SJ, Tassaux D, Vignaux L, Jolliet P, Ceriana $\mathrm{P}$, et al. Automated detection of asynchrony in patient-ventilator interaction. Conf Proc IEEE Eng Med Biol Soc 2009;5324-5327.

46. Cuvelier A, Achour L, Rabarimanantsoa H, Letellier C, Muir JF, Fauroux B. A noninvasive method to identify ineffective triggering in patients with noninvasive pressure support ventilation. Respiration 2010;80(3):198-206.

47. MacIntyre NR, Sessler CN. Are there benefits or harm from pressure targeting during lung-protective ventilation? Respir Care 2010;55(2): 175-180; discussion 180-183.

48. Girault C, Richard JC, Chevron V, Tamion F, Pasquis P, Leroy J, et al. Comparative physiologic effects of noninvasive assist-control and pressure support ventilation in acute hypercapnic respiratory failure. Chest 1997;111(6): 1639-1648

49. Fauroux B, Pigeot J, Polkey MI, Isabey D, Clement A, Lofaso F. In vivo physiologic comparison of two ventilators used for domiciliary ventilation in children with cystic fibrosis. Crit Care Med 2001; 29(11):2097-2105.

50. Jubran A. Inspiratory flow rate: more may not be better. Crit Care Med 1999;27(4):670-671.

51. Corne S, Gillespie D, Roberts D, Younes M. Effect of inspiratory flow rate on respiratory rate in intubated ventilated patients. Am J Respir Crit Care Med 1997;156(1):304-308.

52. Manning HL, Molinary EJ, Leiter JC. Effect of inspiratory flow rate on respiratory sensation and pattern of breathing. Am J Respir Crit Care Med 1995;151(3 Pt 1):751-757.

53. Fernandez R, Mendez M, Younes M. Effect of ventilator flow rate on respiratory timing in normal humans. Am J Respir Crit Care Med 1999;159(3):710-719.

54. Prinianakis G, Delmastro M, Carlucci A, Ceriana P, Nava S. Effect of varying the pressurisation rate during noninvasive pressure support ventilation. Eur Respir J 2004;23(2):314-320.

55. Mehta S, McCool FD, Hill NS. Leak compensation in positive pressure ventilators: a lung model study. Eur Respir J 2001;17(2):259-267.

56. Calderini E, Confalonieri M, Puccio PG, Francavilla N, Stella L, Gregoretti C. Patient-ventilator asynchrony during noninvasive ventilation: the role of expiratory trigger. Intensive Care Med 1999; 25(7):662-667.

57. Battisti A, Tassaux D, Janssens JP, Michotte JB, Jaber S, Jolliet P. Performance characteristics of 10 home mechanical ventilators in pressure-support mode: a comparative bench study. Chest 2005; 127(5):1784-1792. 
58. Hotchkiss JR, Jr., Adams AB, Stone MK, Dries DJ, Marini JJ, Crooke PS. Oscillations and noise: inherent instability of pressure support ventilation? Am J Respir Crit Care Med 2002;165(1):47-53.

59. Adams AB, Bliss PL, Hotchkiss J. Effects of respiratory impedance on the performance of bi-level pressure ventilators. Respir Care 2000; 45(4):390-400.

60. Kacmarek RM. Proportional assist ventilation and neurally adjusted ventilory assist. Respir Care 2011;56(2):140-148; discussion 149152.

61. Gay PC, Hess DR, Hill NS. Noninvasive proportional assist ventilation for acute respiratory insufficiency. Comparison with pressure support ventilation. Am J Respir Crit Care Med 2001;164(9):1606-1611.

62. Banno K, Okamura K, Kryger MH. Adaptive servo-ventilation in patients with idiopathic Cheyne-Stokes breathing. J Clin Sleep Med 2006;2(2):181-186.

63. Fietze I, Blau A, Glos M, Theres H, Baumann G, Penzel T. Bi-level positive pressure ventilation and adaptive servo ventilation in patients with heart failure and Cheyne-Stokes respiration. Sleep Med 2008;9(6):652-659.

64. Han F. New approach for new target: adaptive servo-ventilation on Cheyne-Stokes respiration in congestive heart failure. Chin Med J (Engl) 2006;119(8):619-621.

65. Hastings PC, Vazir A, Meadows GE, Dayer M, Poole-Wilson PA, McIntyre HF, et al. Adaptive servo-ventilation in heart failure patients with sleep apnea: a real world study. Int J Cardiol 2010;139(1):17-24.

66. Kasai T, Narui K, Dohi T, Takaya H, Yanagisawa N, Dungan G, et al. First experience of using new adaptive servo-ventilation device for Cheyne-Stokes respiration with central sleep apnea among Japanese patients with congestive heart failure: report of 4 clinical cases. Circ J 2006;70(9):1148-1154.

67. Kasai T, Usui Y, Yoshioka T, Yanagisawa N, Takata Y, Narui K, et al. Effect of flow-triggered adaptive servo-ventilation compared with continuous positive airway pressure in patients with chronic heart failure with coexisting obstructive sleep apnea and Cheyne-Stokes respiration. Circ Heart Fail 2010;3(1):140-148.

68. Morrell MJ, Meadows GE, Hastings P, Vazir A, Kostikas K, Simonds AK, et al. The effects of adaptive servo ventilation on cerebral vascular reactivity in patients with congestive heart failure and sleepdisordered breathing. Sleep 2007;30(5):648-653.

69. Ono H, Fujimoto H, Kobayashi Y, Kudoh S, Gemma A. Sleep apnea syndrome: central sleep apnea and pulmonary hypertension worsened during treatment with auto-CPAP, but improved by adaptive servo-ventilation. Intern Med 2010;49(5):415-421.

70. Randerath WJ, Galetke W, Kenter M, Richter K, Schafer T. Combined adaptive servo-ventilation and automatic positive airway pressure (anticyclic modulated ventilation) in co-existing obstructive and central sleep apnea syndrome and periodic breathing. Sleep Med 2009;10(8):898-903.

71. Randerath WJ, Galetke W, Stieglitz S, Laumanns C, Schafer T. Adaptive servo-ventilation in patients with coexisting obstructive sleep apnoea/hypopnoea and Cheyne-Stokes respiration. Sleep Med 2008;9(8):823-830.

72. Szollosi I, O'Driscoll DM, Dayer MJ, Coats AJ, Morrell MJ, Simonds AK. Adaptive servo-ventilation and deadspace: effects on central sleep apnoea. J Sleep Res 2006;15(2):199-205.

73. Teschler H, Dohring J, Wang YM, Berthon-Jones M. Adaptive pressure support servo-ventilation: a novel treatment for Cheyne-Stokes respiration in heart failure. Am J Respir Crit Care Med 2001;164(4): 614-619.

74. Mireles-Cabodevila E, Chatburn RL. Work of breathing in adaptive pressure control continuous mandatory ventilation. Respir Care 2009; 54(11):1467-1472.

75. Storre JH, Seuthe B, Fiechter R, Milioglou S, Dreher M, Sorichter S, et al. Average volume-assured pressure support in obesity hypoventilation: a randomized crossover trial. Chest 2006;130(3):815-821.

76. Crisafulli E, Manni G, Kidonias M, Trianni L, Clini EM. Subjective sleep quality during average volume assured pressure support (AVAPS) ventilation in patients with hypercapnic COPD: a physiological pilot study. Lung 2009;187(5):299-305.

77. Branson RD, Gentile MA. Is humidification always necessary during noninvasive ventilation in the hospital? Respir Care 2010;55(2):209216; discussion 216.

78. Lellouche F, Brochard L. Advanced closed loops during mechanical ventilation (PAV, NAVA, ASV, SmartCare). Best Pract Res Clin Anaesthesiol 2009;23(1):81-93.

79. Lellouche F, Maggiore SM, Deye N, Taille S, Pigeot J, Harf A, et al Effect of the humidification device on the work of breathing during noninvasive ventilation. Intensive Care Med 2002;28(11):1582-1589.

80. Jaber S, Chanques G, Matecki S, Ramonatxo M, Souche B, Perrigault $\mathrm{PF}$, et al. Comparison of the effects of heat and moisture exchangers and heated humidifiers on ventilation and gas exchange during non-invasive ventilation. Intensive Care Med 2002;28(11):1590-1594.

81. Raux M, Ray P, Prella M, Duguet A, Demoule A, Similowski T. Cerebral cortex activation during experimentally induced ventilator fighting in normal humans receiving noninvasive mechanical ventilation. Anesthesiology 2007;107(5):746-755.

82. Evans KC, Banzett RB, Adams L, McKay L, Frackowiak RS, Corfield DR. BOLD fMRI identifies limbic, paralimbic, and cerebellar activation during air hunger. J Neurophysiol 2002;88(3):1500-1511.

83. Bennett S, Hurford WE. When should sedation or neuromuscular blockade be used during mechanical ventilation? Respir Care 2011; 56(2):168-176; discussion 176-180.

\section{Discussion}

Epstein: Your very last question, which I think is the most important, was does this impact the failure of NIV? If you were to design such a study, you'd almost be asking the clinicians to not intervene when they found asynchrony, if you really wanted to find out the impact on outcomes. I would imagine most of us would try to fix the ventilator or fix the patient. Any thoughts about how one would design such a study and not intervene?

Hess: I think what we would need to do is collect data during the initiation of NIV that would give us clues to asynchrony, but to have someone who was blinded as to what is going on at the bedside, who would then after the fact evaluate the degree of asynchrony in those in whom NIV was successful and in those in whom it failed.
Epstein: My point is that you showed very nicely that asynchrony is associated with discomfort, so you'd have to say, "I'm not going to fix the ventilator so that the patient's more comfortable."

Hess: But what you have to say is, "I'm going to allow the clinicians to do whatever they do now and then I will after the fact look at the data we collect and determine if there were differences in asynchrony index between 
the successes and failures." That's really quite different than saying, "I'm going to do a study to try and see if we can always have the asynchrony index be $<10$." You could do that as a quality-assurance study and evaluate what is happening now and then implement that kind of a practice and see if your NIV success rate goes up. It would be difficult to do the RCT [randomized controlled trial]. I don't think you could get that through any IRB [institutional review board] to do the trial wherein one group of patients you tried to make as synchronous and comfortable as possible and in the other group you'd ignore thatparticularly with the literature that we have.

Parthasarathy: There might be a little selection bias there. One of the reasons I wanted to look at sleep in mechanically ventilated patients was that Philip Leung found there was a higher likelihood of ineffective trigger efforts at times at night, when things were quiet. ${ }^{1}$ If we looked at the data during their sleep state, I would not be surprised if we found more ineffective triggering during sleep than awake. It's a function of the patient's respiratory drive and auto-PEEP. If auto-PEEP is high or respiratory drive is low, there will be more ineffective triggering. While the patient is awake, by default, the respiratory drive is higher, so there's better synchrony, whereas during sleep respiratory drive is lower, so there's a greater likelihood of nontriggering. Therefore, I have a conceptual problem with these data about discomfort being propagated by ineffective triggering.

About the ethics of planning such a study, I think we currently have equipoise. We don't know whether ineffective efforts and asynchrony are causing poor patient outcomes, so I think if it were phrased appropriately an IRB could approve it, because we don't know if it's a mere phenomenon or causative.
1. Leung P, Jubran A, Tobin MJ. Comparison of assisted ventilator modes on triggering, patient effort, and dyspnea. Am J Respir Crit Care Med. 1997;155(6):1940-1948.

Hess: You could use the Vignaux study $^{1}$ to support that by saying that they showed no effect on outcome as a result of greater number of asynchronies.

1. Vignaux L, Vargas F, Roeseler J, Tassaux D, Thille AW, Kossowsky MP, et al. Patient-ventilator asynchrony during noninvasive ventilation for acute respiratory failure: a multicenter study. Intensive Care Med 2009;35(5):840-846.

Parthasarathy: And in a real world-study, even in the control arm, we can tell the investigators or the physician caring for the patient to go ahead and make whatever adjustments they want within certain parameters, knowing the fact that the physician and the provider will not be able to be there $24 / 7$ making all those adjustments all through the day, as opposed to a device or mode that can make it all go away. You'd also find that you'd get more rich data about the efficacy of operatordriven care versus ventilator settings determined by a fully automated closed-loop system.

Epstein: What we don't know is whether they eventually responded. The one reason that asynchrony may not have been associated with an adverse outcome is that the clinicians went ahead and fixed it.

Hess: And they only looked at a 30minute period of time.

Epstein: Right. In fact, that's a limitations of all these studies, because when we're looking at snapshots in time, we don't know what happened subsequent to that. The clinicians may have intervened, asynchronies may have been reduced, and outcome may have been affected.
Hess: They may have collected their data and then strapped the mask on more tightly.

Hurford: What is the role of the airway? When I ventilate patients in the operating room, whether they're able to have a decent airway or they have a history of sleep apnea or obstructive disease or have a large beard affects my ability to succeed, and I wonder whether any of the studies have looked at that? Also, Rich [Branson] observed that surgical patients don't do well on NIV, but what factors are important in surgical patients, such as obesity or an abdominal incision?

Hess: So, to your first question, there are certainly patients who are more difficult to fit an interface. As far as anybody doing the sorts of upper-airway scoring that you use when you assess a patient for intubation, I don't know if anybody's ever done that during NIV. So there is a research opportunity.

Hurford: We have several scoring systems for difficulty with mask ventilation in the operating room. If a patient is likely to have a lot of difficulty, maybe I should use a different algorithm, depending on underlying patient factors. I'd like to talk about the patient; you've been talking about the machine.

Hess: I like that. I don't think anybody has tried to use any of those scoring systems for difficult mask fit or intubation that you use in the OR [operating room] to try to assess patients in the ICU [intensive care unit] whom we're thinking of putting on NIV. That is a research opportunity. Your second question had to do with whether there are more problems in some...?

Hurford: To follow up on Rich's observation that surgical patients don't do well on NIV: what about underlying patient disease and their ability to tolerate NIV? 
Hess: Yeah, I don't know that that's been studied very well. We have at least one $\mathrm{RCT}^{1}$ that shows that there are better outcomes in patients who develop respiratory failure following lungresection surgery. There is at least one $\mathrm{RCT}^{2}$ and several observational studies $^{3-5}$ about NIV in trauma patients. It may not have been studied as well in surgical patients as in medical patients, but I think it's probably being used increasingly in surgical patients. I'd be interested about your experiences with NIV in the PACU [post-anesthesia care unit]. My observation is that it's being used increasingly in that setting.

1. Auriant I, Jallot A, Hervé P, Cerrina J, Le Roy Ladurie F, Fournier JL, Lescot B, Parquin F. Noninvasive ventilation reduces mortality in acute respiratory failure following lung resection. Am J Respir Crit Care Med 2001;164(7):1231-1235.

2. Hernandez G, Fernandez R, Lopez-Reina P, Cuena R, Pedrosa A, Ortiz R, Hiradier P. Noninvasive ventilation reduces intubation in chest trauma-related hypoxemia: a randomized clinical trial. Chest 2010;137(1):7480 .

3. Xirouchaki N, Kondoudaki E, Anastasaki M, Alexopoulou C, Koumiotaki S, Georgopoulos D. Noninvasive bi-level positive pressure ventilation in patients with blunt thoracic trauma. Respiration 2005;72(5):517-522.

4. Beltrame F, Lucangelo U, Gregori D, Gregoretti C. Noninvasive positive pressure ventilation in trauma patients with acute respiratory failure. Monaldi Arch Chest Dis 1999;54(2):109-114.

5. Gregoretti C, Beltrame F, Lucangelo U, Burbi L, Conti G, Turello M, Gregori D. Physiologic evaluation of noninvasive pressure support ventilation in trauma patients with acute respiratory failure. Intensive Care Med 1998;24(8):785-790.

Hurford: Right. The most common application is the one that you'd think would be the least likely to work, which is in a morbidly obese patient after gas- tric-bypass surgery. Those patients are at high risk for gastric distension, and you'd think that NIV wouldn't work very well, but it works amazingly well. We'll often get someone to go onto NIV preoperatively to get them through the postoperative phase.

Hess: Those are often patients who are not naïve to NIV.

Hurford: Right, because they use CPAP [continuous positive airway pressure] for their OSA [obstructive sleep apnea].

Hess: Or maybe even NIV for their central apneas, perhaps for many years before their surgery.

Epstein: But trauma patients may have a lot of other things going on, including hemodynamic instability, and maybe head and neck trauma, so they're not good candidates. But there are several studies now, both observational and I think there's more than one RCT-you're thinking of the Auriant study ${ }^{1}$ on lung resection, but there's also one from Ranieri's group ${ }^{2}$ on CPAP in postoperative patientsshowing better outcomes.

1. Auriant I, Jallot A, Herve' P, Cerrina J, Le Roy Laduri F, Fournier JL, et al. Noninvasive ventilation reduces mortality in acute respiratory failure following lung resection. Am J Respir Crit Care Med 2001;164(7): 1231-1235.

2. Squadrone V, Cocha M, Cerutti E, Schellino MM, Biolino P, Occella P, et al. Continuous positive airway pressure for treatment of postoperative hypoxemia: a randomized controlled trial. JAMA 2005;293(5):589-595.

Hess: Correct. They used CPAP in patients following abdominal surgery and showed this improved outcome.
Kallet: In our SBT [spontaneous breathing trial] database for qualityassurance we track post-extubation failure with medical and surgical patients, and our use of NIV for postextubation respiratory distress. It's kind of a quick-and-dirty look, but I was surprised at the number of trauma and surgical patients who seemingly were failing extubation where NIV seemed to work and avoided re-intubation. It's not anywhere near a controlled study, but I would say that if we think they're going to fail an extubation trial, why not try NIV? I also think there's a difference between using NIV in a surgical trauma patient initially coming in-and they're maybe getting worse-and someone who's been intubated and in the postextubation period develops distress from secretions or atelectasis. Those are different contexts.

Hess: There's an accumulating evidence base supporting the use of NIV to prevent extubation failure. At least 3 RCTs have come to my mind, including one by Ferrer just a few months ago. ${ }^{1-3}$

1. Nava $S$, Gregoretti C, Fanfulla F, Squadrone E, Grassi M, Carlucci A, Beltrame F, Navalesi $\mathrm{P}$. Noninvasive ventilation to prevent respiratory failure after extubation in highrisk patients. Crit Care Med 2005;33(11): 2465-2470.

2. Ferrer M, Valencia M, Nicolas JM, Bernadich O, Badia JR, Torres A. Early noninvasive ventilation averts extubation failure in patients at risk: a randomized trial. Am J Respir Crit Care Med 2006;173:164-170.

3. Ferrer M, Sellares J, Valencia M, Carrillo A, Gonzalez G, Badia JR, et al. Noninvasive ventilation after extubation in hypercapnic patients with chronic respiratory disorders: randomised controlled trial. Lancet 2009;374(9695): 1082-1088.

This article is approved for Continuing Respiratory Care Education credit. For information and to obtain your CRCE

(free to AARC members) visit

RCJournal.com

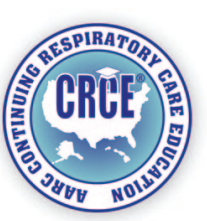

